\title{
LEYES I DECRETOS
}

\author{
DEL
}

\section{SIPRENO GOBIERVO.}

Departamento de Justicia, Culto, e Insiptecien Publiza.

Santiago, diciembre 24 de 1856.

Con lo espuesto en la nota quie precelle,

Ha venido en acordar i decreto :

1. - Establécese en el barrio de Yungai una escuela noctuma para hombres, que funcionará en el lugar que proporcione la Municipalidad, i en la cual se enseñaràn gratuitamente los ramos siguientes : lectura, escritura, aritnética, incluso el sistena decimal i esplicaciones orales de relijion.

2. El mencionado estableciniento serí dirijido por el profesor de la escuela de práctica anexa a la normal, don José Mercedes Mesias, a quien se abonará un sobresueldo de ciento eincuenta pesos antales desde que principie a prestar sus servicios.

3. Concédese una asignacion de ciento cincuenta pesos anuales, para gastos de alumbrado $i$ utencilios de enseñanza, la cual scrá entregala por la Tesorería jeneral anticipadamente cada mes al preceptor, quien rendirá la cuenta respectiva.

4. Autorizase al Intendente de Santiago para que libre contra la Tesorería jeneral hasta la cantidad de treinta pesos, para proveer al establecimiento mencionado de las lámparas yecesarias.

5. - Impútense las sumas decretadas a la partida 56 del presupuesto de Instruccion Pública correspondiente al año próximo entrante. 
6. Aceptando la cooperacion que ofrecen algunos vecinos del barrio de Yungai, el Intendente de Santiago elejirá, de entre ellos, al que juzgare mas a propósito para encargarse especialmente del cuidado i vijilancia de la escuela, i para que recolecte las sumas que se ofrecen destinadas a proveer el referito establecimiento de los útiles necesarios i premiar a los alumnos mas sobresalientes.

Tómese razon i comuníquese.-Montr.-Walio Silva.

Santiago, diciembre 24 de 1856.

A fin de dar a la escuela nocturna i dominical para artesanos de la Recoleta i la de dibujo lineal fundada en el mismo punto una organizacion que consulte mejor la buena disciplina del establecimiento i el mayor aprovechamiento de los alumnos.

\section{He venido en acordar $\mathrm{i}$ decreto :}

1. - La escuela nocturna i dominical para artesanos de la Recoleta i la de dibujo lineal fundada en el mismo barrio formarán un solo establecimiento que funcionará bajo la denominacion de escuela para artesanos de la Recoleta en el local que actualmente ocupan las dos escuelas mencionadas.

En este establecimiento se enseñarán gratuitamente los ramos siguientes : lectura, escritura, aritmética, incluso el sistema métrico decimal, esplicaciones orales de relijion, ejercicios prácticos de ortografia castellana, nociones elementales de jeografia i dibujo lineal.

2. - Los artesanos alumnos de la escuela referida recibirán lecciones todos los mártes, miércoles, juéves i viérnes por la roche durante tres horas, $i$ todos los dias festivo ${ }^{s}$ por la mañana durante cuatro.

3. - La escuela para artesanos de la Recoleta tendrá un director con el sueldo de trescientos pesos anuales, un profesor de dibujo lineal con el de doscientos cuarenta, un primer ayudante con $6 \mathrm{l}$ de doscientos, un segundo con el de ciento veinte $i$ un portero con el de sesenta.

4. - A cargo del director estarán la distribucion del tiempo, el órden interier del establecimiento, i la enseñanza de todos los ramos designados en el art. $1 .^{\circ}$ que desempeñará anxiliado por los ayudantes, ménos el de dibujo lineal que tendrá un profesor especial.

5. Cóncedese una asignacion de veinte $i$ cinco pesos mensuales para gastos de alumbrado $\mathbf{i}$ utensilios de enseñanza que serán proporcionados gratuitamente a los alumos. La Tesorería jeneral entregará por bimestres anticipados, la referida asignacion al Director de la escuela, quien rendirá la cuenta respectiva.

6. - Impútense las cantidades decretaras a $\operatorname{los}$ item $3 .{ }^{\circ}, 4 .^{\circ}, 5 .^{\circ}, 6 .^{\circ}$ i $70^{\circ}$ de la partida 45 del presupuesto del Ministerio de Instruccion pública correspondiente al año venidero $i$ los ciento diez i nueve pesos que faltan a la partida 56 del mismo presupuesto.

7. Nómbrase Director de la mencionada escuela a don Anselmo Albin; profesar de dibujo lineal a don Manuel Salvatierra, prímer ayudante a don José Santiago Muñoz i segundo a don Benjamin Sosa. Autorizase al Director para que nombre al portero. 
8. - Las prescripciones del presente decreto comenzarán a ubservarse desde el 1.0 de enerode 1857 .

9. Quedan derogados todos los decretos que se ban dictado anteriormente sohre ta escuela nocturna i dominical para artesanos de la Retoleta, i la escuela de dibujo lineal establecida en el mismo punto.

Tómese razon i comuniquese.-Montr.-Waldo Silva.

Santiagn, diciembre 29 de 1856 .

Con lo espuesto en la nota que precede, i documentos adjuntos, autorizase al Intendente de Coquimbo para quelibre contra la oficina respectiva hesta la cantilad de trescientos veinte i cinco pesos veinte centavos, a fin de que se adquiera para el gabinete de física del Liceo de la Serena los instrumentos que contiene la adjunta lista, ofrecidos en venta por la testamentaria de don Linis Troncoso. Impuitese al itern 19 de la partila 36 del presupuesto del Ministerio de Instruccion Pública para el año de 1Sô7, rindase la correspondiente cuenta.

Tómese razon i comuniquese.-Monтr.-Wallo Silva.

Santiago, diciembre 31 de 1856.

He acordado i decreto :

Art. I. Los Liceos de provincia tyue hagan sus gastos con fundos propios i que reciban del Gobierno, pasarán en el mes de diciembre de cada año un presupresto detaliado de sus entradas i salidas para obtener la correspondiente aprobacion.

Art. 2. - En el presupvesto se hará figurar los gastos ordinarios, eventuales $i$ estraordinarios qua exijiere el establecimiento, i las inversiones se harán con arreglo a las partidas aprobabas.

Art. 3. - Los Liceos que hasta la fecha no hubiesen furmado presupuesto, Io formarán i remitirán con la brevedad posible.

Anótese i circúlese.-MoNrT.-Walilo Silva. 
Santiago, enero 7 de 1857.

Con lo espuesto en la nota que precede,

He venido en acorlar i decre to :

1. - Establecese en el Olivar, departamento de Caupolican, una escnela para mujeres que funcionará en el local comprado al efectc, debiendo proporcionar los utensilios necesarios.

2. En el mencionado estalulecimiento se ensez̄arán gratuitamente los ramos siguientes : lectura, escritura, catecismo, aritmética, gramática castellana, costura i bordacio.

3. Nómbrase preceptora de la referida escuela a doña Mariana Videla de Liebue, a quien se abonará el sueldo de doscientos pesos anuales desde que principie a prestar sus servicios.

4. - Impútese el sueldo decretado a la partida 56 del presupuesto del Miuisterio de Instruccion Pública.

Tómese razon i comuniquese.-Montr. - Waldo Silva.

Santiago, enero 8 de 1857.

He venido en acordar i decreto :

1. ${ }^{-}$Establécese en el Institato Nacional una biblioteea que se compondrá de los libros que en la actualidad posee el meneionado Colejio, de los que espresa la lista adjunta i de los que pueden adquirirse con la cantidad consultada para este objeto en el presupuesto corriente del Institato Nacional.

El Rector empleara con preferencia dicha suma en la compra de testos de enseñanza i otras obras que puedan servir para ensanchar i perfeccionar el conocimiento de los diversos ramos que abrase el plan de estudios.

2. Nómbrase bibliotecario de la esprcsada biblioteca a don Manuel José Olararrieta quien se recibirá de ella bajo el competente inventario.

3. ${ }^{\circ}$ Abonese al bibliotecario nombrado, descle que principie a prestar sus servicios, un sobresueldo de cincuenta pesos anuales que se sacará por ahora de fondos jenerales del Instituto Nacional, debiendo consultarse en el próximo presupuesto de dicho establecimiento la partida correspondiente.

4. - La referida biblioteca estarí a disposicion de los empleados i alumnos internos i esternos del Instituto Nacional, guienes podrán sacar libros de ella conformándose a las reglas establecilas para las bibliotecas populares por el decreto de 16 de enero de 1856. 
5. El Rector fijará las horas durante las cuales deberá abrirse diariamente dicha biblioteca.

Tómese razon i comuníquese.-MoxTr.-Waldo Silva.

Santiajo, enero 10 de 1857.

Con lo espuesto por el Intendente de Chiloé en su nota núm. 76, fecha 15 de dicienbre último,

He venilo en acordar i decreto :

1. Establécese en Lomi, departamento de Castro, una escuela para mujeres que funcionará en el local provisto de lus utensilios precisos que proporcione la Muniajpalidad o vecindario respectivo, $i$ en la cual se enseñarín gratuitamente los ramos siguientes : lectura, escritura, catecismo, aritmética, gramática castellana, costura i bordado.

2. Autorízase al Intendente de Chiloé, para que nombre, dando cuenta, una preceptora idónea que sirva la espresada escuela.

3. - Abónese a dicha preceptora, desde que principie a prestar sus servicios, el sueldo de doscientos cuarenta pesos anuales, que se imputará a la partida 56 del presupuesto de Instruccion Pública.

Tómese razon i comuníquese.-Montr.—Waldo Silva.

Santiago, enero 10 de 1857.

Con lo espuesto por el Intendente de Chiloé en su nota núm. 76, fecha 15 de diciem. bre último,

He venido en acordar i decreto :

1. Establécese en Rauco, departamento de Castro, una escuela para hombres que funcionará en el local provisto de todos los utensilios precisos que proporcione la MIIricipalidad o vecindario respectivo, $i$ en la cual se enseñanán gratuitamente los ramos siguientes: lectura, escritura, aritmética i gramática castellana.

2. ${ }^{\circ}$ Autorizase al Intendente de Chiloè para que nombre, dando cuenta, una persora idónea que sirva la referida escuela.

3. - Abónese a dicho director desle que principie a prestar sus servicios, el sueldo de doscientos cuarenta pesos anuales, que se imputará a la partida 56 del presupuesto del Ministerio de Instruccion Pública.

Tómese razon i comuníquese.-Moxrt.-Waldo silva. 
Santiago, enero 10 de 1857.

He venido en acordar i decreto:

1. Establécese en el barrio de San Pablo de ezta ciudad, 2. ' Subdelegacion del departamento de Santiago, una esenela para mujeres en la cual se enseñarán gratuitamente los ramos siguientes: lectura, escritara, catecismo, aritmética, gramática castellana, jeografia, costuro i bordado.

2. Nómbrase para que sirva dicha escutla a dona Andrea Navarrete, a quien se abonará el sueldo de trescientos pesos anuales desde que principie a prestar sus servicios.

3. - Señálase a la espresada preceptora una asignacion de de sesenta pesos anuales para pago de alquiler de la casa donde debe funcionar dieha escuela.

4. Entréguese por la Tesurería jeneral al visitadar de escuelus de la provincia de Santiago, la cantidal de setenta pesos, para que rindiendo la correspondiente cuenta prover a la referida escutla de los utenisiljos necesarios.

5. - Impútense las cantidades decretadas a la partila 56 del presujpuesto del Ministerio Instruccion pública.

Tómese razon i comuníquese.-Montr. - Waldo Silva.

\section{Santiago, enero 10 de 1857.}

Con lo espuesto por el Intendente de Concepcion en su nota núm. 160 fúcha 10 de diciembre último,

He venido en acordar i decreto :

1, - Establécese en el puerto de Dichato, departamento de Coelemu una escuela para hombres, que funcionará en eJ Iocal provisto de los útiles precisos que proporcione Ia Municipalidad o vecindario respectivo, i en la cual se enseñarán gratuitamente los ramos siguientes : lectura, escritura, catecismo, aritmética, gramática castellana i jeografía.

2. A Autorizase al Intendente de Coneepcion, para que nombre, dando cuenta, una persona idónea que desempeñe dicha escuela.

3. Abónese a dicho preceptor desde que principie a prestar sus servicios el sueldo de doscientos cuarenta pesos anuales, que se imputará a la particla 56 del presupuesto del Ministerio de Instruccion Pública.

Tómese razon i comuníquese.-Montr.-Waldo Silva. 
Santiago, enero 10 de 1857.

Con lo espuesto por el Intendente de Concepeion en su nota núm. 160 fecha 10 de diciembre último,

He venido en acerlar i decreto :

1. Establécese en Penco, departamento de Coelemu, una escuela para mujeres que funcionará en el local provisto de los utensilios precisos que proporcione la Municipalidad o vecindario respectivo, i en la cual se enseñarán gratuitamente los ramos siguientes : lectura, escritura, catecismo, aritmética, granática castellana, costura i bordado.

2. Autorizase al Intendente de Concepcion para que nombre, daudo cuenta, una persona idónea que desempeñe dicha escuela.

3. - Abónese a dicha preceptora desle que principie a prestar sus servicios tl sueldo de doseientos cuarenta pesos anuales que se imputará a la partida 56 del presupuesto del Ministerio de Instruccion Pública.

Tómese razon i comuniquese.-Mositr.-Waldo Silva.

Santiago, enero 10 de $185 \%$.

Con lo espuesto por el Intendente de Concepcion en su notà núm. 160 fecha 10 de diciembréúltimo,

He venido en acordar $\mathrm{i}$ decreto :

1. E Establécese en Hualqui, departamento de Pucbacai, una escuela para mujeres que funcionará en el Jocal provisto de los utensilios precisos que proporcione la Municipalidad o vecindario respectivo, i en la cual se enseñarán gratuitamente los ramos siguientes : lectura, escritura, catecismo, aritmética, gramática castellana, costura i bordado.

2. A Autorizase al Intendente de Concepcion para que nombre, dando cuenta, una persona idónea que desempeñe dicha escuela.

3. ${ }^{\circ}$ Abónese a dicha preceptora, descle que principie a prestar sus servicios, el sueldo de doscientos cutarenta pesos anuales que se imputará a la partida 56 del presipuesto del Ministerio de Instruccion Pública.

Tómese razon i comuníquese.-Monrt,-Waldo Silva. 


\section{Saniiago, enero 10 de $18 \overline{7}$.}

Con lo espuesto por el Iritendente de Concepcion en su nota número 160 fecha 10 de diciembre último.

He venido en acordar i decreto:

Establécese en Puchacai a inmediaciones del iiclino de este rombre, una escuela para mujeres que funcionará en el local provisto de los itiles precisos que proporcione la Iunicipalidad o vecindario respectivo, i en la cual se eusuriarin grotuitamente los ramos siguientes : lectura, escritura, catecismo, aritmética, gramítica casteilana, costura i bordado.

2. Nómbrase preceptora de dicha escuela a doña Concepcion Acebelo, a quien se abonari el sueho de duscientos cuarenta pesos anuales, desde que principie a prestar sus servicios.

3. - Imputese el suello decretado a la partida 56 del presupuesto del Ministerio de Instruccion Pública.

Tumese razon i comuniquese.-Montr.-Waldo Silva.

Santiago, enero 9 de 1857 .

Con lo espuesto por el Intendente de Chiloé en su nota núm. 76 fecha 5 de diciemjie último,

He venido en acordar i decreta:

1. Establécese en $\mathbb{M}_{a u l l i n}$ departamento de Carelmapu, una escuela para mujeres cue funcionará en el local provisto de los utensilios necesarios gue proporcione la Municipalidad o vecindario respectivo, i en la cual se enserarin gratuitamente los ramios siguientes : lectura, escritura, catecismo, aritmética, gramática castulizna, costara i bordado.

2. Antorizase al Intendente de Cliloé para que nombre, dando cuenta, una persona idónea que sirva la espresada escuela.

3. Abónese a dicha preceptora, desle que principic a prestar sus servicios, el sieldo de doscientos cuarenta pesos anuales que se imputará a la partida 56 del presupuesto del Ministerio de Instruccion Pública.

Tómese razon i comuníquese,-Montr- Hraldo Silla. 


\section{Santiago, enero 13 de 1857.}

Para que la clase de escuitura i dibujo ornamental esté mejor atendida i sea suceptible de mas ensanche,

He acordado i decreto:

Art. 3. La clase de escaltura i dibujo ornamental funcionará en adelante en ez departamento Universitario, bajo Ia inspeccion del Delegado Universitario.

Art. 2. En virtud de esta inspeccion el espresado Delegado dietará las providencias que creyere oportunas para su mejor arreglo i organizacion, distribuyendo el tiempo i dividiendo la claśe en dos o mas secciones si hubiere diversos alumnos que quisieren concurrir a ella.

Art. 3. ${ }^{\circ}$ Al fin de cada año se espondrán los trabajos ejecutados i los alnmnos harán manifesta ion práctica del estado de adelanto en que se encontraren.

Art. 4. ${ }^{\circ} \mathrm{Al}$ fin de cada curso se dará al alumno mas distinguido una melalla de primera clase, $i$ al que ocupare el segundo lugar una du segunda. Tanto a los dos mencionados como a los demas que lubieren terminado el curso de escultura i dibujo ornamental se les entregará un điploma que así lo acredite.

No habrá en esta clase mas premio que los espresados en el inciso anterior; pero al fin de cada año se publicará la lista de los que se hubieren distinguido en ella por su aprovechamiento $\mathrm{i}$ buena comportacion.

Art. 5. ${ }^{\circ}$ Los fondos presupuestados para pagar al profesor de la clase de escultura se entregarán por los Ministros de la Tesorería Jeneral al Tesorero del Instituto Nacional para yue, por la oficina de este establecimiento se haga al profesor nombrado el correspondieste pago.

Tómese razon i comuníquese.-Moxтt.-Waldo Silva.

Santiago, enero 14 de 1857 .

Con lo espuesto por el Intendente de Colchagua en su nota número 105 fecha 5 de : diciembre último,

He venido en acordar i decreto:

1. Establécese en la orilla de Tinguirixica, departamento de San Fernando, una escuela para mujeres en la cual se ensefiarán gratuitamente los ramos siguientes : lectura, escritura, catecismo, aritmética, gramática castellana, costura i bordado.

2. Acéptase la oferta de los vecinos de dicho punto para proporcionar por shora i en lo sucesivo, a la mencionada escuela el local i los utensilios precisos, debiendo refaccionarlos o renovarlos cuando fuere necesario. 
3. Autorízase al Intendente de Colchagua para que nombre, dando cuenta, une persona idónea que sirva dicha escuela.

4. - Abónese a la preceptora mencionada el sueldo de doscientos cuarenta pesos anuales, que se imputará a la partida 56 del presupuesto del Ministerio de Instruccion Pública.

5. El referido Intendente comunicará al Ministerio de Instruccion Públiea el dia en que la indicada escuela principie a fancionar i el número de alumnos con que se hubiere abierto.

Tómese razon i comuníquese.-Moxrr.-Waldo Silva.

Santiago, enero $1 \pm$ de 1857.

Con lo espuesto por el Intendente de Colchagua en su nota núm. 195, fecha 5 de diciembre último,

He verido en acordar i decreto: :

1. Establécese en Vichuquen, departamento de Curicó, una escuela para mujeres en la cual se enseñarán gratuitamente los ramos siguientes: lectura, escritura, catecismo, aritmética, gramática castellana, costura i bordado.

2. Acéptase la oferta de los vecinos de dicho punto para proporcionar por ahora i en lo sucesivo a la mencionada escuela el locai i los utensilios precisos, debiendo refaccionarlos o renovarlos cuando fuere necesario.

3. Autorízase al Intendente de Colchagua para que nombre, dando cuenta, una persona idónea que sirva dicha escuela.

4. - Abónese a la preceptora mencionada, el sueldo de doscientos cuarenta pesos anuales que se imputará a la partida 56 del presupuesto del Ministerio de Instruccion Pública.

5. - El referido Intendente comunicará al Ministerio de Instruccion Pública, el dia en que la indicada escuela principie a funcionar i el número de alumnas con que se hubiere abierto.

Tómese razon i comuníquese.-MoNTr.-Waldo Silva

Santiago, enero 11 de 1857.

Con lo espuesto por el Intendente de Colchagua en su nota núm. 195 fecha 5 de diciembre ultimo,

He venido en acordar i decreto :

d. E Establecese en Auquinco, departamento de Curicó, una escuela para hombres 
en la 'cual'se ensènarán gratuitamente los ramos siguientes : lectura, escritura, catecismo, aritmética, gramática castellana i jeogrofía.

2. = Acéntase la oferta de los vecinos de dicho punto para proporcionar por ahora $i$ en lo sucesivo a la mencionada esenela el local i los utensilios precisos, debiendo renoTin'lus o refaccionarlos chando fuere neceiario.

3. Autorizase al Intendente de Colchagna para que nombre, dando cuenta, una persona jlónea que sirva dicla escuela.

4. Abónese al preceptor mencionado el sueldo de doscientos cuarenta pesos anuales, que se imputará a la partida 50 del presupuesto del Ministerio de 1 nstruceion Pública.

5. - El referido Intendente comunieará al Ministerio de Instruccion Pública el dia en que la indicada escueia prineipie a fuzcionar, i el número de alumnos con que se hubiere abierto.

Tómese razon j comuniquese-Moxrt.-Waldo Silva.

\section{Santiago, enero 16 de $18 \overline{7}$.}

Con lo espuesto por el Intendente de Coquimbo en su nota número I fecha 3 del qua rije.

He venido en acordar i lecreto:

1. - Establécess en Clañaral Alto, departanento de Combarbalá nna escuela para hombres en in cual se elseñaran gratuitamente los ramos siguientes : lectura, escritura, catecismo, nritmética, graniática castellana i jeografra.

2. Acéptase la oferta de la Municijalidad de licho departamento para proporcionar por ahora i en lo sucesivo a la mencionada escuela el local i los utensilios preeisos, debiento refaccionarlos o renovarlos cuando fuere necesario.

3. A Atorizase al Intendente de Coquimuo para que nombre, dando cuenta, una persona jlúnea que descroprine la espresada escuela.

4. A Abúnese al preceptur referdo desle que principie a prestar sus servicios, el szeldo de trescientos pesos anuales, que se imputará a la partida 56 del presupuesto del Ministerio de Instruccion Pública.

5. - El referido Intendente comunicará a dicho Ministerio el dia en que la indica* ta escuela principic a funcionar i el número de alumnos con que se lubiere abierto.

Tónese razon i comuniguese-Norrt.-Waldo Silva. 
Santiago, enero 16 de 1857.

Con lo espuesto por el Intendente de Corumbo en su nota núm. I fecha 3 del que rije,

He venido en acordar i decreto:

1. Establécese en Recoleta, departamento de Ovalle, una escuela para Lombres, en la cual se ensenarán gratuitamente los ramos siguientes: lectura, escritura, catecismo, aritmética, gramática custellana i jeogrofia.

2. ${ }^{2}$ Aéptuse la oferta de la Menieipalidud de dicho departamento, para proporcionar por ahora i en lo sucesivo a la mencionada escucha, el local i los utensilios precisos, deliendo refaccionarlos o renovarlos cnanio fuere necesario.

3. 'Autorízase al Intendente de Coquimbo, para que nombre, dando cuenta, una rersona idónea que desempeñe la espresada escuela.

4. A Abónese al preceptor referido desle que principie a prestar sus servicios el sueldo de trescientos pesos anuales, que se imputará a la partida 56 del presupuesto del Ministerio de Instruecion Pública.

5. - El referilo Intendente comunicará a dicho Ministerio, el dia en que la indicada escuela principie a funcionar i el número de alumnos con que se hubiere abierto.

Tómese razon i conuníquese.-Mostr.--Waldo Silva.

Stmtiago, cnero 10 de 185\%.

Con lo espuesto por el Intendente de Coquiribo on su nota núm. 1, fecha 3 del. gue rije,

He venicio en acordar $\mathrm{i}$ decreto :

1. F Establecese en Latorre, departamento de Oville, una es vala para hombres en la cual se enseñarán gratuitanente los ramos siguientes: lectura, escritura, catecismo, aritmética, gramática castellana i jeografía.

2. ${ }^{-}$Acćptase la oferta de la Municipalidal de dicho departamento para proporcio. nar por ahora i en lo sucesivo a la mencionada escuela el local i los utentilios irecisos, debiendo refaccionarlos a renovarios cuando futere necestrio.

3. Antorizase al Intendente de Coquinio nama fie nombrc, dondio cuentil, una persona idónea que desempeñe la espresada escuela. 
4. - Abónese al preceptor referido desde que principie a prestar sts servicios, el sueldo de trescientos -pesos anuales, que se imputará a la partida 56 del presupuesto del Ministerio de Instruccion Pública.

5. - El referido Intendente comunicará a dicho Ministerio el dia en que la indicada escuela principie a funcionar, i el número de alumnos con que se hubiere abierto.

Tómese razon i comuniquese.-MoxTr,-Waldo Silva.

\section{Santiago, enero 19 de 1857 .}

Con lo espuesto en la nota que precede i documentos adjuntos;

He venido en acordar i decreto:

1. Establécese en Tilama, departamento de Petorca, una escuela para hombres en la cual se enseñaxán gratuitamente los ramos siguientes : lectura, escritura, catecismo, aritmética, gramática castellana i jeografia.

2. Acéptase la oferta del subdelegado de dicho punto, don José Mranıel Suarez, para proporcionar a la referida escuela el local i los utensilios precisıs, que en lo sucesivo serán refaccionados o renovados cuando fuere necesario, por la Municipalidad o vecindario respectivo, caso de no hacerlo el espresado subdelegado.

3. Nómbrase preceptor de la escuela de Tilama, a don Agustin liebbe, a quien se abonará desde que principie a prestar sus servicios, el sueldo de trescientos pesos anuales.

4. - Impútese el sueldo decretado a la partida 56 del presupuesto del Ministerio de Instruceion Pública.

5. - El Intendente de Aconcagua comunicará a dieho Ministerio el día en que la indicala escuela principie a funcionar, i el núnsero de alumnos con que se hubiere abierto.

Tómese razon i comaníquese.-Monrr.-Waldo Siiva.

Santiago, enero 20 de 1857 .

Con lo espuesto en la nota que precede del Gobernador de Comburbalá,

He venido en acordar i decreto:

1. Establecese en la villa de Combarbalá una escuela nocturna para hombres, 
que estará anexa a la escuela modelo de dicho punto, i en la cual se enseñarán gratuitamente los ramos siguientes: lectara, escritura, aritmética, incluso el sistema métrica decimal i esplicaciones orales de relijion.

2. Nómbrase al preceptor de la escuela modelo de la misma villa don José Leaniro Maturana, para que dirija la referida escuela, con un sobresueldo de cien pesos *nuales que-se le abonará desde esta fecha.

3. 9 Concédese una asignacion de cincuenta pesos anuales para gastos de alumbrado i utensilios de enseñanza, la cual será entregada por la oficina pagadora respectiva anticipadamente eada mes al preceptor nombrado, quien rendirá la correspondiente cuenta.

4. Dutorizase al Intendente de Coquimbo para que libre contra la oficina respectiva, hasta la centidad de cincuenta pesos para proveer a la indicada escuela de los. mucbles precisos, debiendo rendir la correspondiente cuenta.

Impútense las cantidades decretadas a la partida 56 del presupuesto del Ministerio. de Instruccion pública.

Túmese razon i comuníquese.-Morrt.-Waldo Silva.

Santiago, enero 28 de $185 \%$.

Con lo espuesto en la nota precedente,

Hé acordado i decreto:

1. Establécese en la subdelegacion 19, denominada Donigïe, departamento de Rancagua, una escuela para mujeres en la cual se enseñarán gratnitamente los ramos siguientes: lectura, escritura, catecismo, aritmética, gramática castellena, costura i bordado.

2. Acéptase la oferta de los vecinos de dicho punto para proporcionar por ahora i en lo sucesivo a la mencionada escuela, el local i los útiles precisos, debiendo refacciouarlos o renovarlos cuando fiere necesario.

3. Nómbrase a doña Mercedes Ponce, para que desempeñe esta escuela.

4. Abónese a la referida preceptora el sueldo de doscientos cuarenta pesos anuales que se imputará a la partida 56 del presupuesto del Ministerio de Instruccion pública.

5. - El Intendente de Santiago conunicará al espresado Miristerio el dia en que esta escuela principie a funcionar, i el número de alumnas con que se hubiere abierto.

Tómese razon i comuniquese.-Moxtr.-Waldo Silva. 
Santiago, enero 30 de 1857.

Con lo espitesto por el hutendente de Áconcagua en su nota 22 del actual nú: $\mathrm{S}$.

He acordacloi decreto:

1. F Fistablécese en Chincoleo, departamento de Petorea, una escneli para hombres en la cual se enseñarán gratuitamente los ramos signtin tica, gramitica costellana i jeografía.

2. Esta escuela funcionará en el lonal ofrecido por la Municipalilad i veaindario respectivo, concelliéndose por unasola vez trinta pesos para útiles de cote estableci. miento. En Io silcesivo sera de cuenta de la espresada Municipulidad i vecindario, ta refaccion del local i útiles referidos.

3. Fómbrase a don José Marmlan para que desempeñe esta escuela.

4. Abónese a dicho preeptor el sueldo de doscientos cuarenta pesos anuales, i entríguesele por la respectiva Tesorería de Hinistros, los referidos treinta pesas, bajo la correspondiente cuenta de inpersion, imputindose ímbas cantiuades a la partida 56 de? presupusto del Fininisterio de instruecion pública.

5. - El referido Inteddente comunicará al espresado Ministerio el din en que ests. escuela principie a funcionar $i$ sl número de alumnos con que se habiere abierto.

Tomese razon i comuniquese.-Moxtr. - Waldo Silva.

Suntiago, fcbrero s de $185 \pi$.

De acuerdo con el Cónsejo de Estado, vengo en aprobar on tulus sus partes los sî. guientes

\section{ESTATUTOS}

\section{De la Societdad de Instruccion primaria de Concepcion.}

Art. 1.0 Se estalliece en Consepcion una societhd que tiene por objeto lifundir protejor por tolos los medios que estén a sus alcances la instruccinia prinaria.

Art. 2. - La scciedud se compondrí de los inlividuos que han siscrito la acta de instalocion i de los que firmen los presentes estatutos, eomo tombien de aruellos que se incorperen con arreglo a ellos. 
Art. 3. Se establece como base de la sociedad la suscripeion mensual de cincuenta centavos, que será obligatoria para los socios, sin perjuicio de la mayor cuctí con que cada uno de ellos quiera contribuir i de las erogaciones voluntarias de los demas vecinos, aun cuando no sean socit $;$, i sin limitacion de cantidad, por pequeña que sea. La cuota será pagaula por semetres articípalos.

Art. 4: - La asociucion será representada por un Directorio, compuesto de quince socios, elejidos por ella misma a pluralidad de votos entre los concurrentes. Las funciones de este durarán dos años, i sus miembros podrán ser reelejidos indefinilumerte.

Art. 5. - El Intendente de la provincia serú miembro i presidente nato del Directorio como tambièn de las reuniones jenerales. Tambien hará parte del directorio la comision Mrnicipal de inspeccion de eseuelas, i los miembros de la junta provincial de educacion, nomórados por la Universidad.

Art. 6. Son atribuciones del directorio:

1. E Elejir de su scno un Vice-Presidente i un Tesorero, i de entre los niembros de la sociedal, dos Secretarios, in pectores de escuelits, i las demas comisioncs que se cre-

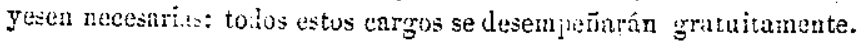

2. Nombrar los empleados subalternos que f(teren necesarios i desiguar sus sucldos.

3. Penover los empleados a que se refiere el inciso precudente.

4. Establecer i dirijir las escuel:as, designar los locales en que deben establecerse, darles nombre i dietar los reglamentos porque deban rejirse.

5. Procurar la introduccion de naevos socios, i admitir a los que soliciten serlo.

6. Arbitrar la colectacion de fondos, administurlos $\mathrm{i}$ procurar su incremento.

$7 .=$ Formar los reglamentos económicos i determinur las atuibuciones $\mathrm{i}$ deberes le los empleados.

Art. $7{ }^{\circ}$ El Directorio darí chenta a Ia socielad en sus reuniones ordinarias, de las entradas, gastos i trabajos que se hubieren practicado, i pubiicará por trinestres un estado parcial gue contenga estog mismos datos.

Art. 8. - Eas reuniones ordinarias del Directorio, tendrán lugar el primero i tercer doningo de cada mes, i las estraordinarias, cuana el Presidente lo tuviere conveuiente, o lo soliciten tres miembros del directorio.

Ant. 9. Constituye sala Ia reunioa de siete miembros del Directorio.

Art. 10. Para que sean válidos los aeuerdos del Directorio, se requiere mayoria absoluta de votos entre los miembros presentes.

Art. 11. En los primeros quince dias del mes de setiembre, habrá anualmente uni reunion jeneral ordinaria, o en los subsiguientes si hubiere imposibilidad; pudiendo el presidente citar a Ias estraordinarjas que taviere a bien.

\section{Artículo transitorio.}

Se pentrú en conocimiento del Consejo Universitario ja instalacion ile la sociedad, i se pedirá al Supremo Gobierno Ia aprobacion de los presentes Estatutos.

Anótese, comuniquese i publípueze,-Moxzt,-Waldo Silva. 
Santiago, febrero 3 de $185 \%$.

De acuerlo con el Consejo de Estado, vengo en aprobar en todas sus partes Ios si-
guientes

\section{ESTATUTOS}

\section{De la Sociedad de instruccion primaria de Ancud.}

Art. 1. Se establese en Ancud una soeiedad que tiene por objeto difundir en el pueblo la instruccion primaria, procurando aumentar la concurren cia a las escuelus es. tablecidas, creando otras a su costa i tomentando asociaciones análogas en las demas. localidades de la provincia.

Art. 2.0 Todo individuo perteneciente a la sociedad deberá contribuir con una chota menual de cincuenta centavos que satisfurá por trinestres anticipados, sin perjuicio de las erogaciones voluntarias de las personas filantrópicas. La cuota designada podrá limitarse a veinte centavos pagadera en la miswa forma, euando lo solicitare el contribuyente al incorporarse a la socielad.

Art. 3. - La asociacion será representada por un directorio compuesto del $O$ bispo de la diócesis, el rejidor protector de escuelas, diez socios elejidos por la misma sociedad a jluralidad de votos i la junta de educacion de la provincia. Las funciones de los socios que se nombraren para componer el directorio durarán por dos años i podrán ser reelejidos indefinidamente.

Art. 4. ${ }^{\circ}$ El Intendente de la provincia será miembro i Presidente nato de la asociacion $i$ del directorio.

Art. 5.० Son atribuciones del directorio.

1. - Elejir de su seño un vice-presidente, secretario, pro-secretarie, tesorero e inspector de escuelas, cuyos cargos se desempeñarán gratuitamente.

2. Nombrar los demas empleados mubalternos que sean necesarios i designar sus sueldos.

3. - Remover los empleados a que se refieren los dos incisos precedentes.

4. ${ }^{\circ}$ Establecer i dirijir las escuelas, designar los Iocales en que deban situarse, darles nombre i dictar los reglamentos porque deban rejirse.

5. Procurar la introduccion de nuevos socios i admitir los que soliciten serlo.

6. Arbitrar la coleccion de fondos, administrarlos i procurar su incrensento.

7. Formar los reglamentos económicos i determinar las atribuciones i deberes de los empleados.

8. Separar de la sociedad, si lo tiene a bien, a aquellos socios que no pagaren su cuota durante un trimestre, como tambien a los que por algun otro motivo se hagan indignos de pertenecer a la sociedad. 
Art. 6. Son deberes del directorio dar cuenta a la sociedad en sus renniones ordinarias de las entradas, gastos i trabajos que hubieren tenido lugar, i publicar anualmexte un estado parcial que contenga estos mismos datos.

Art. 7. - Las remiones ordinarias del directorio tendrán lugar los dias $10^{\circ}$ i 15 de cada mes, sin perjuicio de las estraordinarias a que el Presidente tuviera a bien convoear.

Art. 8. - Para que sean válitas las resoluciones del directorio se requiere mayoría absoluta de sufrajios entre los miembros presentes, lus que en ningun caso podrán ser ménos de siete.

Art. 9. Ea el mes de setiembre de cada año i en el dia que determine el Presidente, habrá una junta jenteral ordinaria. El Presidente podrá tambien citai a las tstraordinarias que turiera a bien.

Ar. 10. Se pondrá en conocimiento del eonsejo universitario la instalacion de la sociedad, i se solicitará del Supremo Gobierno la aprobaciun de los presentes estatutos.

Anótese, comuniquese i publiquese.-Montт.-Waldo Silva.

Falparaiso, febrero 18 de $185 \tilde{i}$.

Con lo espuesto en la nota adjunta a la que precede,

He venido en acordar i decreto:

1. Establécese en Quillon, segunda subdelegacion del departamento de Puchacai, una escuela para mujeres en la cual se enseñarán gratuitamente los ramos siguientes: lectura, escritura, catecismo, aritmética, gramática castellaua, costura i bordado.

2. - Acéptase la oferta de la Municipalidad i vecindario de dicho punto para proporcionar por ahora i en to sucesivo a la mencienada escuela el local i los utensilios precisos, debiendo refaccionarlos o renovarlos cuando fuere necesario.

3. Nömbrase preceptora del referido establecimiento a doña Eulojia Mora, a quien se abonará desde que principie a prestar sus servicios, el sueldo de dosciestos cuarenta pesos anuales que se imputará a la partida 56 del presupuesto del Ministerio de Instruccion pública.

4. ${ }^{-}$El Intendente de Concepcion comunicará al Ministerio de Instruccion pública El dia en que la indicada escuela principie a funcionar i el número de alumnas con que se hubiere abierto.

Tómese razon i comuniquese.-Montr.-Waldo silna.. 
Santiago, fubrero 10 de $185 \pi$.

No habiena completalo todavía el nümero ile miembros que el Gobieno paedé nombrar en la Facultad de medicina de la Lniversiba de Chile eugun la lei da 19 de noviembre de 1S:2, nómbransé miembros de la espresada Fankltad a don Gui!lemo

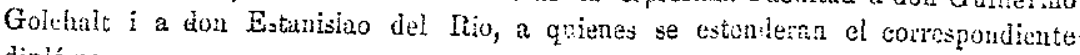
diplóna.

Comuníquese.-Moxтr. - Waldo Silva.

Stantiago, febrero :s de 1857 .

Con lo espuesto en la nota que precede $i$ documentos adjuntos,

Ele venido en acorlan i decreto:

1. Establécese anexa a la escuela fiscal de Talonhuno una escucla nocturna para adultos en la cual se enseñarán gratuitamente Ios ramos siguientes : lectura, escritura, esplicaciones orales de relijion, aritmética, ortografia eastellana i dibujo lineal.

2. Acéptase la oferta de la Municipalidad de dicho junto para proporcionar a la referida escuela el alumbrado $i$ los utensilios de enseñanz necesarios.

3. Nómbrase para que sirva el espresado estableciniento al preceptor de la escuela de Talcahuano don Pastor Roman, a quien se abonará desde que principie a prestar sus servicios, el sobresueldo de cien pesos anuales que se impatará a la partida 56 del presupuesto del Ministerio ds Instruccion Pública.

Tómese razon i comuníquese.-Mortr.-Wulló Silia.

Suntiago, mar*o 7 de $185 \pi$.

Establecese en la sesion preparatoria del Instituto Nacional una clase de ilioma ale. nan cuyo profesor gozará un sucldo de cuatrocientos plesos antales

Tómese razon i comuníquese.-Moxtr.-Waldo Silea. 
Santiagn, marzo 12 de $18 \overline{7} 7$.

Con lo espuesto en la nota que precede,

He venido en acorilar i decreto :

1. Establécese en la ciulad de Son Felipe ma escuela rocturna para aduitos, ea la cual se ensentirán gratuitamente los rumos siguentes: lectura, escritura, esplica-

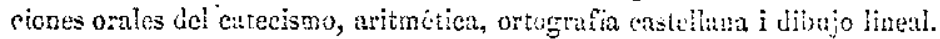

2. = Actiptase la oferta que hace el comendalor de hia Merded de dicha ciudad, para que proporcione el local provisto de los atenilios necesarios dunde debe funcionar el uuevo estublecimiento.

3. N Númbrase para quie dirija dicha escuela al preceptor don Juan José Velis, a quien se abonarí, desdis que principie a prestar sus servicios, un subre-suelto de cien pesos nnuales, que se imputará a la partida 56 del presupuesto del Ministerio de Instruccion Pública.

4. El Litendente de Aconcagua comunicará al espresado Ministerio el dia en que la espresadia escuela principie a funcionar, i el núnero de alunos con que se hubiere abierto.

Tómese razon i comuníquese-Moxry, - Waldo Silza.

Santiago, murzo 13 de 18577.

Con lo espuesto por el Intendente de Aconcagua cn nota 22 de enero último, núm. $S$,

He venido en acordar i decreto :

1. - Establécese en la Placilla, departamento de la Ligua, una escuela para mujares que funcionará en el local provisto de los utensilios necesarios que proporcione la Municipulidad o vecindario respectivo, i en la cun se enseñuráil gratuitanente los ramus siguientes: lectura, escritura, catecismo, aritmética, gramática castellana, costura i bordado.

2. Concédese por una soli vez la cantidad de veinte i cinco pesos para ayudar a ia adquisicion do Ios muebles que fueren precisos para dicho establecimiento, debiendo rendirse In correspondiente cuenta de la inversion de esta suma.

3. Autorízase al Intendente de Aconcagua para que norsbre, dando cuenta, una 
preceptora :jónea a quien se abonará desde que principie a prestar sus servicios ế sueldo de doscientos cuarenta pesos anuales.

4. - Impútense las sumas decretadas a la partida 56 del presupuesto del Ministerio de Instruccion pública.

5. El referido Intendente comunicará al espresarbo Ministerio el dia en que la nueva escuela principie a funcionar, $\mathrm{i}$ el número de alumnas con que se hubiere abierto.

Témese rezon i comuníquese.--Mortr.-Waldo Silua.

Santiago, marzo 18 de 185 \%.

He renido en acordar i decreto:

1. - Establécese una escuela para hombres em la subdelegacion del Papal del departamento de Chillan, que funcionará en el local provisto de los utensilios necesarios que proporcione la Municipalidad o vecindario respectiro, i en la cual se enseñarán gratuitamente los ramos siguientes : lectura, escritura, catecismo, aritmética, gramática castellana i jeografia.

2. Nórabrase preceptor de dicha eseuela a don Vicente Ascui, a quien se abonará desde que principie a prestar sus servicios el sueldo de doscientos cuarenta pesos anuales que se imputarí a la partida 56 del presupuesto del Ministerio de Instruccion Pública.

8. - El Intendente del F̃uble comunicará al espresado Ministerio el dia en que la nueva escuela comience a funcionar, i el número de alumnos con que se hubiere abierto.

Tómese razon i comuríquese.-Montr.-Waldo Silva.

Santiago, marzo 20 de $185 \%$.

Con lo espuesto en la nota que precede, se declara que los diplómas de doctor en Medicina espedidos por la Universidad de Kiel en Holstein, serán por sí solos comprobantes de que el que los ha obtenido ha hecho los estudios suficientes para ser admitido desce luego a rendir las pruebas oral i por escrito que exije el reglamento de grados.

: Tómese razon i comuníquese.-MonTr.-Waldo Silva. 
Santiago, mario 20 de 1857.

Cun lo espuesto en la nota que precede, i considerando que el Derecho Civil Español será de pura aplicacion para los alumnos que deben cursarlo en el presente año, ea la época que hayan conelnido su curso con arreglo al plan de estudios de la instruccion superior,

He acordado i decreto:

Art. 1. - Suprínase el estudio de Derecho Civíl Español del plan de estudios decretado en 7 de dicienbre de 1853, el cusl será reemplazado en adelante por el Derecho Civíl Chileno.

Art. 2. Para la colacion de grados universitarios se exijirán certificados de exámenes de Derecho Civil Español solo en los años de 1857 i 1858.

Tómese razon i comuníquese.-Moxtr.-Waldo Silva.

Santiago, marzo 23 de 1857.

Con lo espuesto en la nota que precede,

He venido en acordar $i$ decreto:

7. - Establésese en el barrio de Yungai de esta ciudad una escuela para niños que funcionará en el local de la escuela nocturna de adultos creada en el mismo punto, i en la cual se enseñaran gratuitamente los ramos siguientes: lectura, escritura, catecismo, aritmética, gramatica castellana, jeografia i dibujo lineal.

2. ${ }^{\circ}$ Nómbrase preceptor de dicha esicuela al antiguo alumno de la Escuela Normal o actual preceptor de la escuela de Casuto, don Indalecio Murúa, a quien se abanará el sueldo de trescientos pesos anuales desde que principie a prestar sus servicios.

3. I Impútese el sueldo decretado a la partida 56 del presupuesto del Ministerio de Iasstruecion Pública.

4. - El Intendente de Santiago comunicará al referido Ministerio el dia en que principie a funcionar la nueva escuela, i el número de alumnos con que se hubiere abierto.

Tómese razon i comuníquese.--MoNrT.-Waldo Silva. 